\title{
ORIGINAL ARTICLE Timeline of changes in appetite during weight loss with a ketogenic diet
}

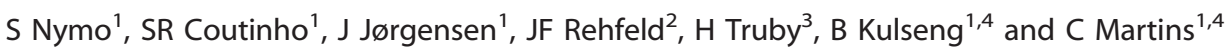

BACKGROUND/OBJECTIVE: Diet-induced weight loss (WL) leads to increased hunger and reduced fullness feelings, increased ghrelin and reduced satiety peptides concentration (glucagon-like peptide-1 (GLP-1), cholecystokinin (CCK) and peptide YY (PYY)). Ketogenic diets seem to minimise or supress some of these responses. The aim of this study was to determine the timeline over which changes in appetite occur during progressive WL with a ketogenic very-low-energy diet (VLED).

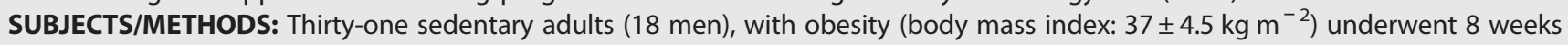
(wks) of a VLED followed by 4 wks of weight maintenance. Body weight and composition, subjective feelings of appetite and appetite-related hormones (insulin, active ghrelin (AG), active GLP-1, total PYY and CCK) were measured in fasting and postprandially, at baseline, on day 3 of the diet, 5 and $10 \% W L$, and at wks 9 and 13. Data are shown as mean \pm s.d. RESULTS: A significant increase in fasting hunger was observed by day 3 ( $2 \pm 1 \% \mathrm{WL}),(P<0.01), 5 \% \mathrm{WL}(12 \pm 8$ days) $(P<0.05)$ and wk $13(17 \pm 2 \% \mathrm{WL})(P<0.05)$. Increased desire to eat was observed by day $3(P<0.01)$ and $5 \%$ WL $(P<0.05)$. Postprandial prospective food consumption was significantly reduced at wk $9(16 \pm 2 \% \mathrm{WL})(P<0.01)$. Basal total PYY was significantly reduced at $10 \% \mathrm{WL}$ (32 \pm 8 days) $(P<0.05)$. Postprandial active GLP-1 was increased at $5 \% \mathrm{WL}(P<0.01)$ and CCK reduced at 5 and $10 \% \mathrm{WL}$ $(P<0.01$, for both) and wk $9(P<0.001)$. Basal and postprandial AG were significantly increased at wk $13(P<0.001$, both). CONCLUSIONS: WL with a ketogenic VLED transiently increases the drive to eat up to 3 weeks (5\% WL). After that, and while participants are ketotic, a 10-17\% WL is not associated with increased appetite. However, hunger feelings and AG concentrations increase significantly from baseline, once refeeding occurs.

International Journal of Obesity (2017) 41, 1224-1231; doi:10.1038/ijo.2017.96

\section{INTRODUCTION}

Obesity has reached epidemic proportions worldwide and is associated with negative public health consequences and large socioeconomic costs. ${ }^{1}$ A weight loss (WL) between 5 and $10 \%$ of baseline weight, if sustained, can have large health benefits by preventing or improving several obesity-related risk factors and comorbidities. $^{2}$ Even though this can be achieved in the shortterm with lifestyle interventions, ${ }^{3}$ most adults will experience weight regain in the long term. ${ }^{3-5}$

Maintaining lost weight is physiologically challenging, as dietinduced WL is associated with compensatory responses on both sides of the energy balance equation. ${ }^{6}$ These responses are driven by a cross talk between the gut and the brain, leading to an increase in appetite and reduction in satiety, ${ }_{10}^{7-9}$ concomitant with an overall reduction in energy expenditure. ${ }^{10-12}$ These mechanisms can reduce $\mathrm{WL}$ rate and increases the risk of relapse. ${ }^{9}$ An increase in ghrelin plasma concentration ${ }^{13-15}$ and a reduction in the concentration of several satiety hormones, such as peptide $Y Y$ (PYY), glucagon-like peptide-1 (GLP-1) $)^{13,16-18}$ and cholecystokinin $(C C K)^{13,19}$ has also been reported with diet-induced WL.

To our knowledge, no studies to date have determined how appetite is affected with progressive WL. With a WL of only $1-2 \mathrm{~kg}$ being shown to increase subjective feelings of hunger, ${ }^{20}$ and a WL of $0.8 \mathrm{~kg}$ associated with an increase in postprandial total ghrelin and a reduction in subjective feelings of fullness, ${ }^{21}$ it is not surprising that adults find WL maintenance extremely hard. However, when carbohydrates and/or energy (using a very-lowenergy diet (VLED)) are restricted sufficiently to induce ketosis, the increase in appetite seen with WL appears to be absent. ${ }^{12,22}$ This has contributed to the generalised idea that ketogenic diets are easy to follow. Most of the studies looking at the impact of WL induced with ketogenic diets on appetite have, nevertheless, been done in females ${ }^{22}$ and none has investigated how long time does it take for appetite suppression to occur under ketogenic diets. Therefore, the primary aim of this study was to assess the timeline over which changes in both subjective feelings of appetite and appetite-related hormones are activated during WL with a ketogenic VLED. A secondary aim was to assess if males and females respond differently.

\section{MATERIALS AND METHODS}

\section{Participants}

Healthy adults with obesity $\left(30<\mathrm{BMl}<45 \mathrm{~kg} \mathrm{~m}^{-2}\right)$ were recruited via newspaper advertising serving the community of Trondheim, Norway. The study was approved by the regional ethics committee (Ref., 2012/1901). The study was registered in ClinicalTrial.gov (NCT01834859), and conducted according to the guidelines laid down in the Declaration of Helsinki. All participants provided written informed consent before commencement.

${ }^{1}$ Faculty of Medicine, Department of Cancer Research and Molecular Medicine, Norwegian University of Science and Technology (NTNU), Obesity Research Group ${ }_{\text {" Trondheim, }}$ Norway; ${ }^{2}$ Department of Clinical Biochemistry, Rigshospitalet, University of Copenhagen, Copenhagen, Denmark; ${ }^{3}$ Department of Nutrition, Dietetics \& Food, Monash University, Melbourne, Victoria, Australia and ${ }^{4}$ Centre for Obesity and Innovation (ObeCe), Clinic of Surgery, St. Olav University Hospital, Trondheim, Norway. Correspondence: 5 Nymo, Faculty of Medicine, Department of Cancer Research and Molecular Medicine, Norwegian University of Science and Technology, Obesity Research Group , Forsyningssenteret, Prinsesse Kristinas gate 5, Trondheim 7030, Norway.

E-mail: siren.nymo@ntnu.no

Received 31 October 2016; revised 22 March 2017; accepted 2 April 2017; accepted article preview online 25 April 2017 ; advance online publication, 16 May 2017 
Participants were required to be weight stable ( $<2 \mathrm{~kg}$ body weight change over the last 3 months), not currently dieting to lose weight, and with a sedentary lifestyle (not engaged in strenuous work or in regular brisk leisure time exercise more than once a week or in light exercise for more than $20 \mathrm{~min}$ per day in more than 3 times per week). Due to the known effect of phase of menstrual cycle on appetite ${ }^{23}$ females had to be postmenopausal or taking hormonal contraceptives. Exclusion criteria were pregnancy, breastfeeding and clinically significant illness including diabetes, previous WL surgery and/or medication known to affect appetite/ metabolism or induce WL.

\section{Study design}

This was a longitudinal intervention study with repeated measurements. Participants were provided with an 8-week ketogenic VLED, followed by 4 weeks of weight stabilisation, and were requested not to change their physical activity levels throughout the study (Supplementary Figure I).

\section{Detailed protocol}

Weight loss phase. Participants followed for 8 weeks a ketogenic VLED (Allevo, Karo Pharma AS, Sweden) with 550/660 kcal per day for females and males, respectively (macronutrient composition: carbohydrates $42 \%$, protein $36 \%$, fat $18 \%$ and fibre $4 \%$ ). No energy fluids were allowed ad libitum. Intake of low-starch vegetables ( $\max 100 \mathrm{~g}$ per day) was encouraged, to provide dietary fibre.

\section{Weight stabilisation phase}

At week 9, participants were gradually introduced to normal food, while reducing intake of the VLED products. An individual diet plan was prescribed by a trained dietician tailored to individual energy requirements (measured resting metabolic rate (RMR) $\times$ physical activity level (PAL) (extracted from individual physical activity monitors (BodyMedia, SenseWear, Pittsburgh, PA, USA) at week 8)), with $15-20 \%$ protein, $20-30 \%$ fat and $50-60 \%$ carbohydrates, aimed at weight stabilisation. ${ }^{24}$

\section{Objective measures of compliance}

Diet: Participants met every week for an individual 20 min consultation with a dietician, to review their food records. Urine acetoacetic acid concentration was also measured weekly, using Ketostix reagent strips. Participants who were not ketotic on more than one occasion were considered not compliant and were excluded from the analysis. Concentration of plasma $\beta$-hydroxybutyric acid $(\beta-\mathrm{HB})$ in the fasting state was also measured with a Ketone Body Assay Kit (Mark134, Sigma-Aldrich, St Louis, MO, USA) at baseline, day 3, 5 and 10\% WL and weeks 9 and 13 .

Physical activity: Armbands were used for 7 days at baseline, weeks 4, 8 and 12. Data were considered valid if participants wore the device for $\geqslant 4$ days, including at least 1 weekend day, on more than $95 \%$ ( $22.8 \mathrm{~h}$ per day) of the time. ${ }^{25}$

\section{Data collection}

The following measurements were performed in fasting at baseline, day 3 of the VLED, when each individual participant reached 5 and $10 \% \mathrm{WL}$, and at weeks 9 (the day immediately after the end of the VLED) and 13.

Body weight and composition. Air displacement plethysmography (BodPod, COSMED, Rome, Italy) was used.

Appetite measures. Subjective appetite feelings (hunger, fullness, desire to eat and prospective food consumption (PFC)) were measured using a validated $10 \mathrm{~cm}$ visual analogue scale ${ }^{26}$ and blood samples were collected in fasting and every $30 \mathrm{~min}(0,30,60,90,120$ and $150 \mathrm{~min})$ after a standardised breakfast $(600 \mathrm{kcal}: 17 \%$ protein, $35 \%$ fat and $48 \%$ carbohydrates), for a period of $2.5 \mathrm{~h}$. Plasma samples were analysed for active ghrelin (AG), total PYY, active GLP-1 and insulin using a Human Metabolic Hormone Magnetic Bead Panel (LINCOplex Kit, Millipore, St Louis, MO, USA) and CCK using an "in-house" RIA method ${ }^{27}$ (intraand inter-assay coefficient of variation were $<10 \%$ and $<20 \%$ for AG, GLP-1 and PYY; $<10 \%$ and $<15 \%$ for insulin and $<5 \%$ and $<15 \%$ for CCK, respectively).
Power calculation

Sample size estimation was based on expected changes (from baseline) in fasting AG plasma concentration overtime (day 3: 27; 5 and 10\%: 0; week 9: 4 and week 13: $53 \mathrm{pmolI}^{-1}$ ). Having into consideration that no previous studies have been done in this area, we used data from Sumithran et $a .^{12}$ for weeks 9 and 13 and hypothesised that there would be an increase in AG on day 3 (approximately half of that seen on week 13) and no changes at 5 and $10 \%$ WL (given that participants would be under ketosis). For a SD of 89 pmol $I^{-1}, 12$ a power of $80 \%$, a significance level of $5 \%$ and assuming a low correlation between time points $(r=0.3), 32$ participants would be necessary.

Statistical analysis

Statistical analysis was performed with SPSS version 22 (SPSS Inc., Chicago, IL, USA), and data presented as estimated marginal means \pm s.e.m., with the exception of BMl, age, average time to achieve 5 and $10 \% \mathrm{WL}$ and $\mathrm{WL}(\%)$ at day 3 , weeks 9 and 13, where means \pm s.d. are given. Statistical significance was set at $P<0.05$. Data were analysed using linear mixed-effects models, with restricted maximum likelihood estimation, including fixed effects for time and sex, and their interaction. Bonferroni correction was used for post hoc pairwise comparisons. The Benjamini-Hochberg method, which controls for the false discovery rate was used to adjust for the fact that we have looked at a large number of outcome variables. ${ }^{28}$ Analyses of fasting and 2.5-h postprandial hormone profile for AG and subjective feelings of hunger were also carried out by linear mixed-effects models (fixed effects for sampling time points $(0,30,60,90,120$ and $150 \mathrm{~min})$, time (baseline, day 3,5 and 10\% WL and wks 9 and 13), sex and interactions).

Weight at baseline was used as a covariate in the linear mixed-effects models when looking at changes in subjective and objective measures of appetite. Given that this did not change the significance of the results; the unadjusted values are presented. Total area under the curve for subjective feelings of appetite and appetite hormones was calculated from 0 to 150 min using the trapezoid rule. Participants with available data on at least three out of the six time points were considered completers.

\section{RESULTS}

Participants

Thirty-three participants met study entry criteria and 31 (13 females, 6 postmenopausal) were included in the analysis (one female withdrew due to personal reasons and one male due to not tolerating the VLED (verified incidence of vomiting, dizziness and fatigue)). Completers had an average BMI of $36.7 \pm 4.5 \mathrm{~kg} \mathrm{~m}^{-2}$ and a mean age of $43 \pm 10$ years. Males were heavier and with greater FFM $(\mathrm{kg})$ than females $(P<0.01$ and $P<0.001$, respectively), but there were no significant differences in age or $\mathrm{BMI}$ between sexes (Supplementary Table I ).

\section{Objective measures of compliance}

Diet: Compliance with the VLED was excellent and no participant was excluded based on not being compliant. Participants were already ketotic at day $3\left(0.60 \pm 0.13 \mathrm{mmoll}^{-1}\right.$ of $\left.\beta-\mathrm{HB}\right)$, even though $\beta-\mathrm{HB}$ plasma concentrations were only significantly increased, compared with baseline, at 5\% WL ( $12 \pm 8$ days) $(P<0.001$ for all, males and females), and continued increased up to week $9(16 \pm 2 \%$ WL) $(P<0.001$ for all, males and females) (Figure 1$)$.

Physical activity: All participants were sedentary at baseline and there were no significant changes over time in any PA variable studied (Supplementary Table II ).

\section{Body weight and composition}

A significant main effect of time, sex and interaction $(P<0.001$, $P<0.05$ and $P<0.001$, respectively) was found for body weight. WL was already significant $(P<0.001)$ on day 3 in all participants and males ( $2 \pm 1 \% \mathrm{WL}$ for both) and body weight continued decreasing progressively, but with no significant differences between week 9 and $13(16 \pm 2 \%$ and $17 \pm 2 \% W L$, respectively) (Figure 2a). About 5\% WL was achieved on day $12 \pm 6$ (11 \pm 5 and 


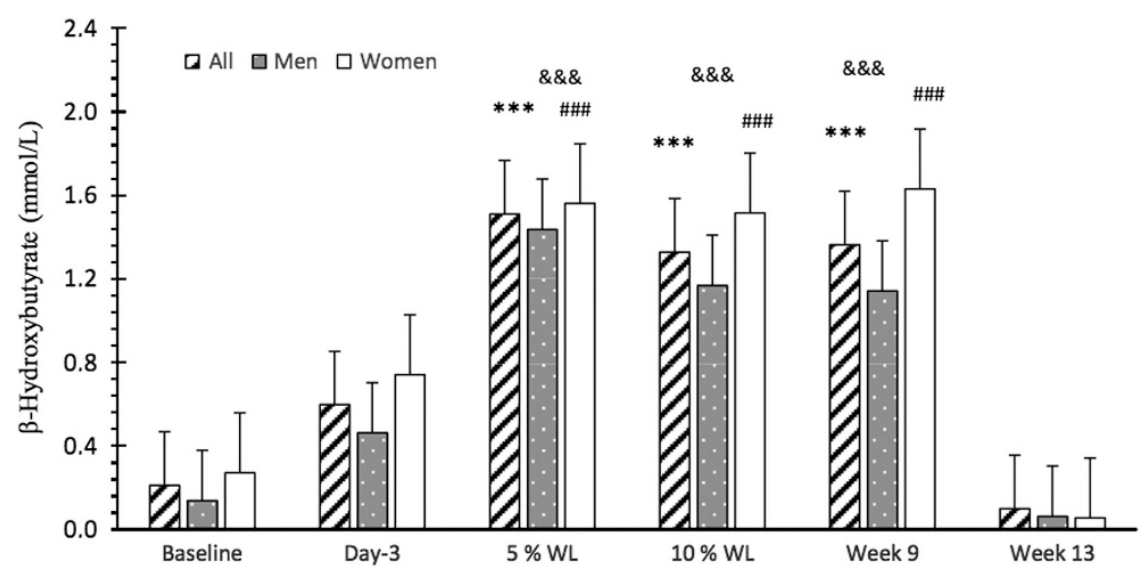

Figure 1. Basal plasma concentration of $\beta$-hydroxybutyric acid over time in all participants, males and females. Results presented as estimated marginal means \pm s.e.m. A significant main effect of time was found for $\beta$-hydroxybutyrate $(P<0.001)$. Symbols denote significant differences from baseline in all participants ${ }^{* * *} P<0.001$, males ${ }^{\& \& \&} P<0.001$ and females ${ }^{\# \#} P<0.001$. WL, weight loss
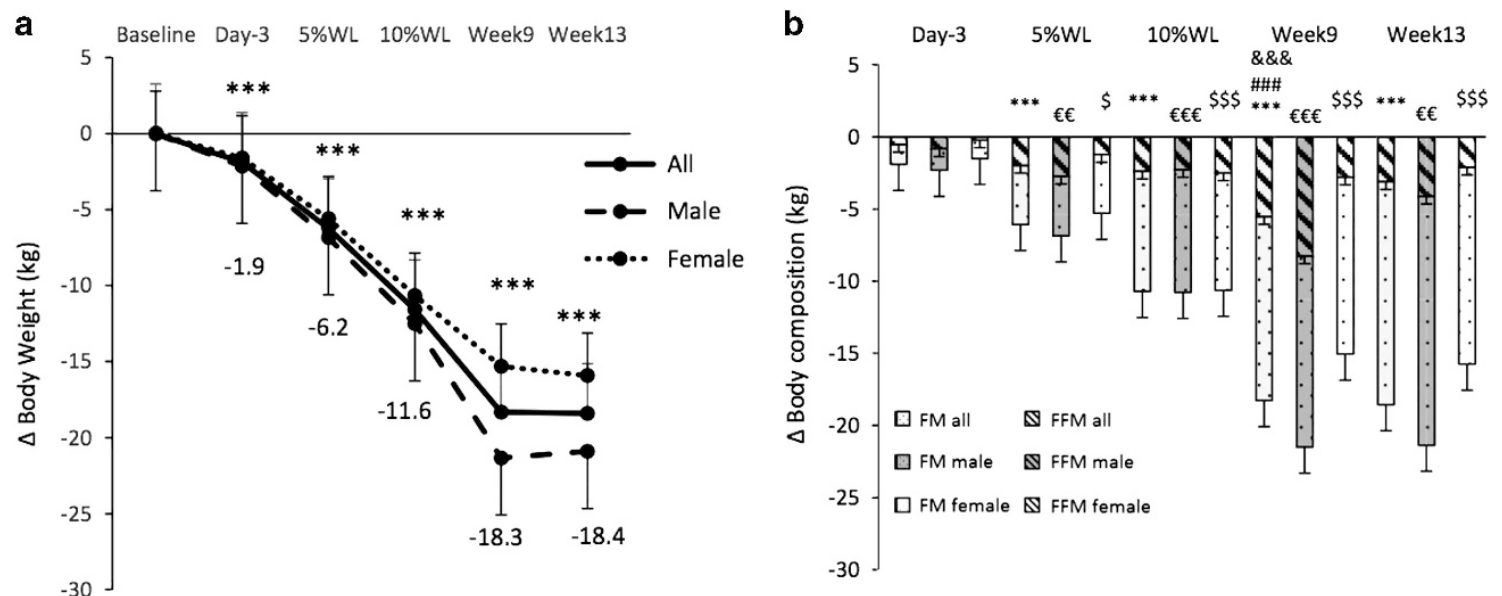

Figure 2. Changes in body weight (a) and body composition (b) over time in all participants, males and females. Results are presented as estimated marginal means \pm s.e.m. Symbols denote significant changes from baseline (all participants: ${ }^{* * * P}<0.001$ for body weight and FM and ${ }^{\# \#} P<0.001$ for FFM; males: ${ }^{\& \& \&} P<0.001$ for FFM and ${ }^{€ \in} P<0.001$, and ${ }^{€ \epsilon} P<0.01$ for FM and females: ${ }^{\$ \$} P<0.001$ and ${ }^{\$} P<0.05$ for FM). FFM, fat-free mass; FM, fat mass; WL, weight loss.

$15 \pm 7$, for males and females, respectively) and $10 \% \mathrm{WL}$ on day $32 \pm 8$ ( $28 \pm 7$ and $37 \pm 6$ for males and females, respectively). Overall WL $(\mathrm{kg})$ was significantly larger in males compared with females $(P<0.001)$, and also at weeks 9 and $13(P<0.001$ for both). When WL was expressed in \% there were no overall significant sex differences $(P=0.053)$, but at week $9(P<0.01)$ males had a significantly larger WL than females.

FM $(\mathrm{kg})$ decreased significantly for the first time after 5\% WL ( $12 \pm 8$ days) $(P<0.001$ for all participants, $P<0.01$ for males and $P<0.05$ for females) and was significantly lower than baseline at all the other subsequent time points (Figure $2 b$ ).

There was a significant decrease in FFM $(\mathrm{kg})$ for the first time at week $9(16 \pm 2 \% \mathrm{WL})$, in all participants and in males $(5.8 \pm 1.0 \mathrm{~kg}$ and $8.3 \pm 1.4 \mathrm{~kg}$, respectively, $P<0.001$ for both). FFM (kg) was never significantly lower than baseline in females (Figure $2 b$ ).

Appetite feelings

Fasting feelings of appetite in all participants and by sex are reported in Figure 3.

A significant main effect of time, but no main effect of sex or interaction, was found for hunger and desire to eat in fasting $(P<0.01$, for both). Feelings of hunger in fasting were significantly increased, compared to baseline, at day $3(2 \pm 1 \% \mathrm{WL})(P<0.01)$, after 5\% WL $(12 \pm 8$ days) $(P<0.05)$ and at week $13(17 \pm 2 \% \mathrm{WL})$ $(P<0.05)$ in all participants. In women, fasting hunger was significantly increased on day 3 and week $13(P<0.01$ and $P<0.05$, respectively). In men, no significant changes were seen at any time point. Feelings of desire to eat were significantly increased at day 3 and after 5\% WL in all participants $(P<0.01$ and $P<0.05$, respectively) and males $(P<0.05$ for both). For feelings of PFC in fasting, there was a significant main effect of time only $(P<0.05)$. However, no significant differences were found between baseline and any other time point. Men reported greater feelings of PFC in fasting overall $(6.8 \pm 0.4$ vs $5.5 \pm 0.4 \mathrm{~cm}, P=0.05)$. No significant main effect of time, sex or interaction was found for feelings of fullness in fasting.

AUC for subjective feelings of appetite overtime is reported in Figure 4. A significant main effect of sex, but no main effect of time or interaction was found for hunger AUC $(P<0.01)$. A significant main effect of time and sex was found for fullness AUC $(P<0.01$ and $P<0.001$, respectively), desire to eat $(P<0.05$ for both) and PFC $(P<0.001$ and $P<0.01$, respectively). No significant differences were found between baseline and any other time point for hunger AUC, desire to eat or fullness. PFC AUC was significantly lower at week $9(16 \pm 2 \% \mathrm{WL})$, compared with baseline in all participants and females $(P<0.01$ and $P<0.05$, respectively). Males had significantly 
a
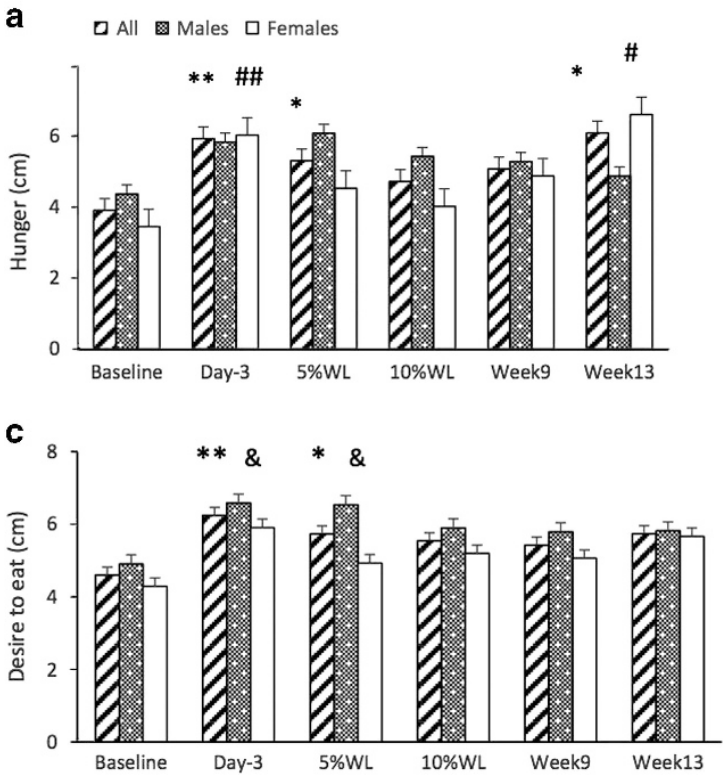

b

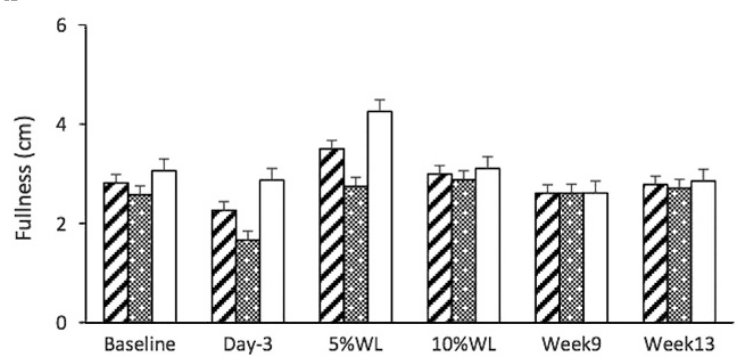

d

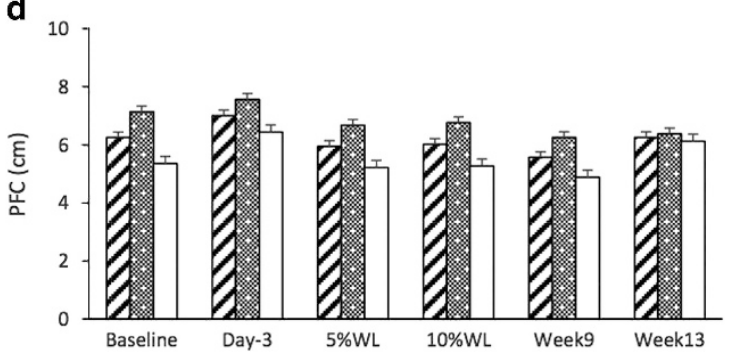

Figure 3. Subjective feelings of appetite (a: hunger, b: fullness, c: desire to eat and d: PFC) in fasting, over time, in all participants, males and females. Results presented as estimated marginal means \pm s.e.m. Symbols denote significant differences from baseline in all participants: ${ }^{* *} P<0.01$ and ${ }^{*} P<0.05$, males: ${ }^{*} P<0.05$ and females: ${ }^{\# \#} P<0.01$ and ${ }^{\#} P<0.05$. PFC, prospective food consumption; WL, weight loss.

a

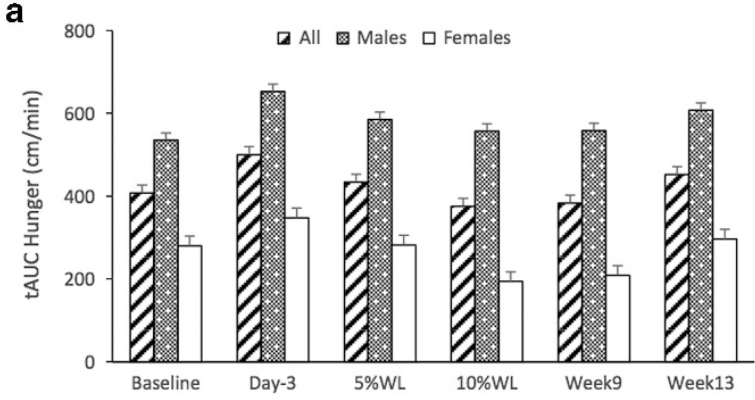

c

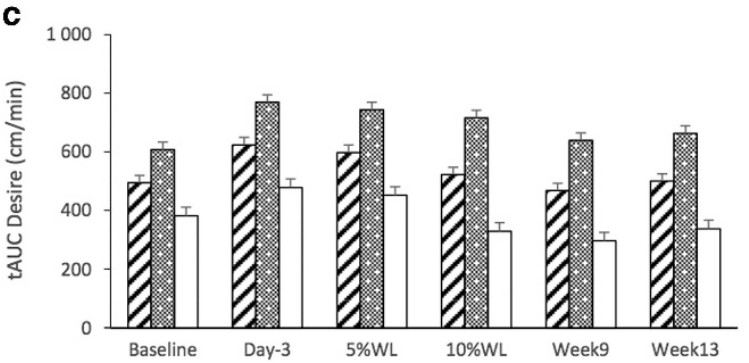

b

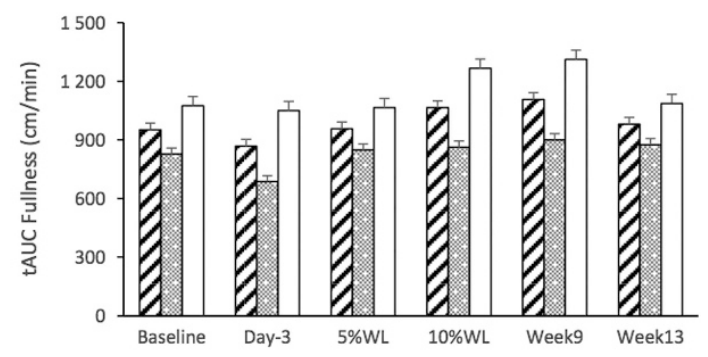

d

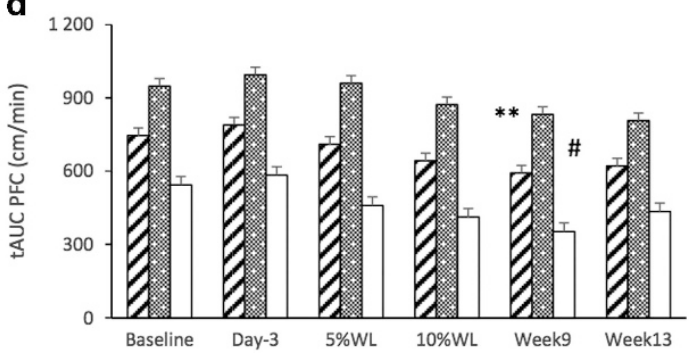

Figure 4. AUC for subjective feelings of appetite (a: hunger, b: fullness, c: desire to eat and d: PFC) over time in all participants, males and females. Results presented as estimated marginal means \pm s.e.m. Symbols denote significant differences from baseline in all participants: ${ }^{* *} P<0.01$ and females: ${ }^{\#} P<0.05$. AUC, total area under the curve; PFC, prospective food consumption; WL, weight loss.

higher overall hunger AUC $\left(582.2 \pm 52.4\right.$ vs $267.18 \pm 61.8 \mathrm{~cm} \mathrm{~min}^{-1}$, respectively), PFC AUC $\left(904.1 \pm 80.9\right.$ vs $459.8 \pm 95.2 \mathrm{~cm} \mathrm{~min}^{-1}$, respectively) and desire to eat $(689.1 \pm 72.1$ vs $380.1 \pm$ $84.8 \mathrm{~cm} \mathrm{~min}^{-1}$, respectively), compared to females. Females had significantly higher fullness AUC $(832.6 \pm 35.9$ vs $1149.7 \pm$ $42.3 \mathrm{~cm} \mathrm{~min}^{-1}$, respectively), compared to males.

Fasting and 2.5-h postprandial hunger feelings can be seen in Supplementary Figure II.

\section{Appetite regulating hormones}

Basal plasma concentration of appetite-related hormones overtime is reported in Figure 5. There was a significant main effect of time, sex and interaction $(P<0.001, P<0.01, P<0.05$, respectively) for basal AG. There was a significant increase in basal AG compared to baseline only on week $13(16 \pm 2 \% \mathrm{WL})$ in all participants, females $(P<0.001$ for both) and males $(P<0.05)$. Basal AG concentration was significantly lower overall in males compared with females $\left(69.2 \pm 8.3\right.$ vs $110.3 \pm 10.2 \mathrm{pmoll}^{-1}$, respectively). No significant main effects of time, sex or interaction were found for basal active GLP-1 or CCK. A significant main effect of time $(P<0.05)$, but no main effect of sex or interaction was found for basal total PYY. A significant decrease in basal active GLP-1 was seen at $10 \%$ WL ( $32 \pm 8$ days) and at week $9(16 \% \mathrm{WL})$, compared with baseline, in males only $(P<0.05$ for both). 


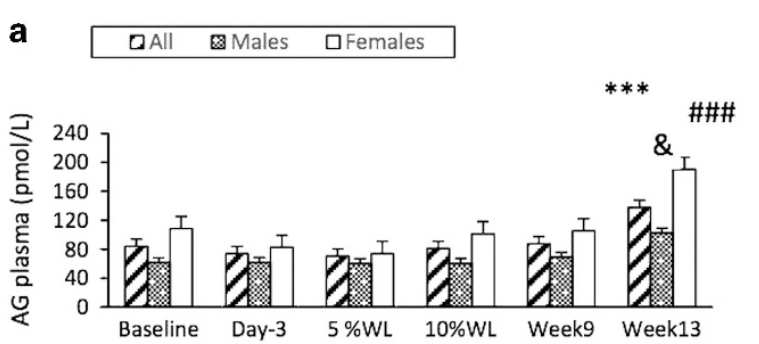

c

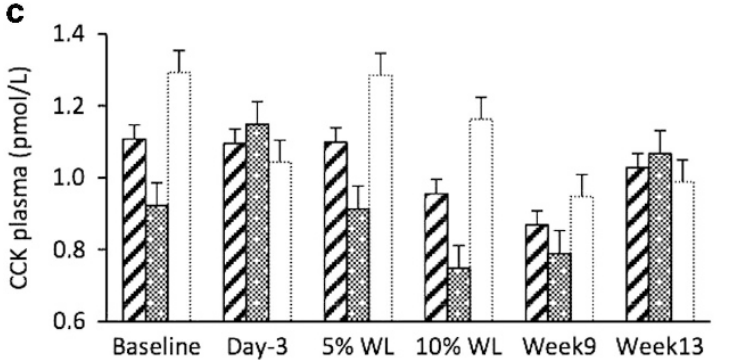

b

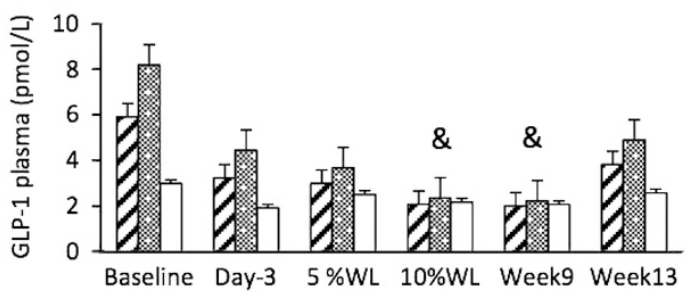

d

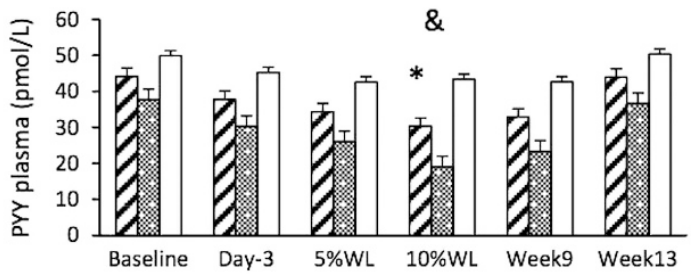

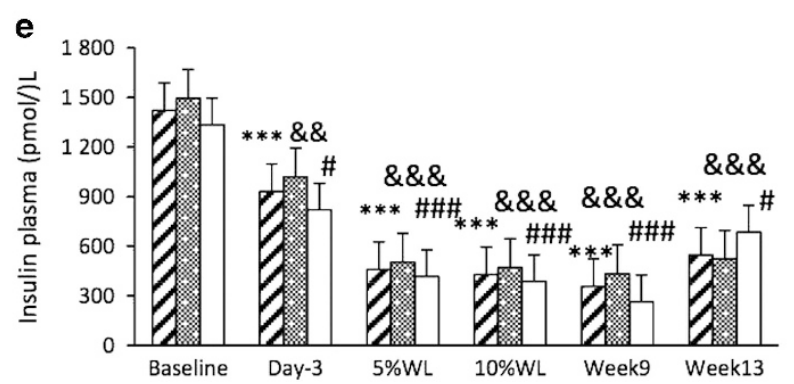

Figure 5. Basal plasma concentrations of appetite-related hormones (a: active ghrelin (AG), b: GLP-1, c: CCK, d: PYY and e: insulin) over time in all participants, males and females. Results presented as estimated marginal means \pm s.e.m. Symbols denote significant differences from

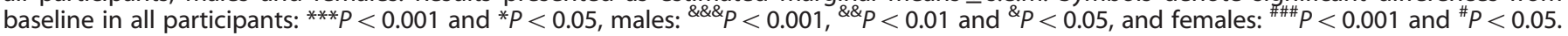
CCK, cholecystokinin; GLP-1, glucagon-like peptide-1; PYY, total peptide YY; WL, weight loss.

A significant reduction in basal PYY was present only after $10 \% \mathrm{WL}$ ( $32 \pm 8$ days), when compared with baseline, in all participants and males $(P<0.05$ for both). A significant main effect of time $(P<0.001)$, but no effect of sex or interaction was found for basal insulin. There was a significant reduction in basal insulin, compared to baseline, for the first time at day 3 , in all participants, males and females $(P<0.001, P<0.01$ and $P<0.05$, respectively), which persisted thereafter.

AUC for appetite-related hormones overtime is reported in Figure 6. A significant main effect of time was found for AG AUC $(P<0.001)$. AG AUC was significantly increased at week $13(17 \pm 2 \%$ $\mathrm{WL})$ in all participants, males and females $(P<0.001$ for all participants and $P<0.05$ for males and females). A significant main effect of time, but no sex or interaction, was seen for active GLP-1, insulin and CCK AUC $(P<0.01, P<0.001$ and $P<0.001$, respectively). Active GLP-1 AUC was only significantly increased after $5 \%$ WL $(12 \pm 8$ days $)$ in all participants $(P<0.01)$. In females, GLP-1 AUC was significantly higher than baseline at $5 \%$ and week 9 $(16 \pm 2 \% \mathrm{WL})(P<0.05$, for both). CCK AUC was significantly reduced at 5 and $10 \%$ WL ( $32 \pm 8$ days) $(P<0.01$ for both), and week 9 $(P<0.001)$ in all participants and $5 \% \mathrm{WL}$ and week 9 in males $(P<0.01$ for both). A significant main effect of time $(P<0.05)$, but no main effect of sex or interaction, was found for PYY AUC. There was only a significant increase between baseline and week 9 $(P<0.05)$ in females. Insulin AUC was significantly reduced at all time points except day 3 in all participants and males, $(P<0.001$ for all) and in females at 5 and $10 \% \mathrm{WL}$ and week $9(P<0.05$ for all).

Fasting and 2.5-h postprandial AG concentrations can be seen in Supplementary Figure III.

\section{DISCUSSION}

In this novel study investigating progressive changes in appetite in adults during a ketogenic WL diet, both subjective feelings of hunger and desire to eat were significantly increased at day 3 $(2 \pm 1 \% \mathrm{WL})$, but were not accompanied by significant changes in physiological appetite hormones except for insulin. This occurred despite participants being already ketotic ( $\beta$-HB plasma concentration $0.60 \pm 0.13 \mathrm{mmol}^{-1}$ ). Previous studies looking at the impact of an acute period of energy restriction on appetite in people with normal weight and overweight (ranging from 1 to 4 days; between 60 and $85 \%$ energy restriction and inducing a WL between 0.8 and $2.4 \mathrm{~kg}$ ) report an increase in feelings of hunger (desire to eat and PFC), both in the fasting and postprandial state. ${ }^{29-32}$ Interestingly, these were not accompanied by changes in either $\mathrm{AG}^{29}$ total ghrelin ${ }^{31,32}$ or GLP-1, ${ }^{29}$ which is in line with our findings. However, the study from Pasiakos et al. ${ }^{21}$ showed a significant increase in postprandial total ghrelin after 2 days on a $321 \mathrm{kcal}$ diet in individuals with normal weight (12 males and 1 female). The different hormone fraction, lower BMl, lower energy intake and different sex distribution compared to our study probably accounts for some of these differences. However, in our study sex responses were apparent. Males (which would be more easily comparable with Pasiakos and colleagues study ${ }^{33}$ ), displayed no changes in AG. ${ }^{21}$ Unfortunately, none of the previously mentioned studies measured ketosis during WL.

After $5 \%$ WL ( $12 \pm 8$ days), feelings of hunger and desire to eat in fasting remained elevated, GLP-1 AUC had increased significantly and CCK AUC was significantly reduced. After $10 \% \mathrm{WL}$ (32 \pm 8 days), no significant changes in subjective feelings of 
a

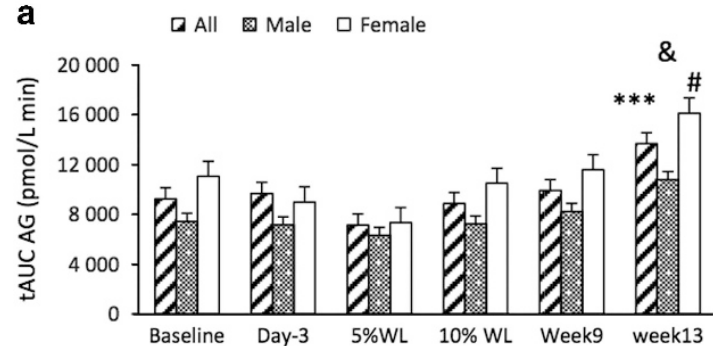

C

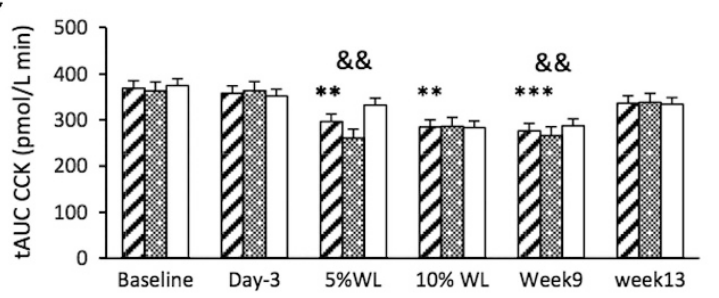

b

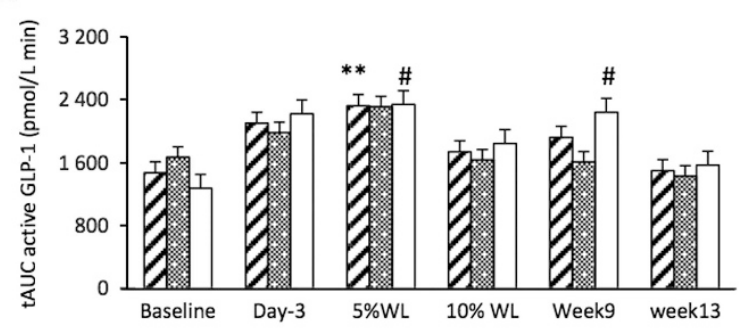

d

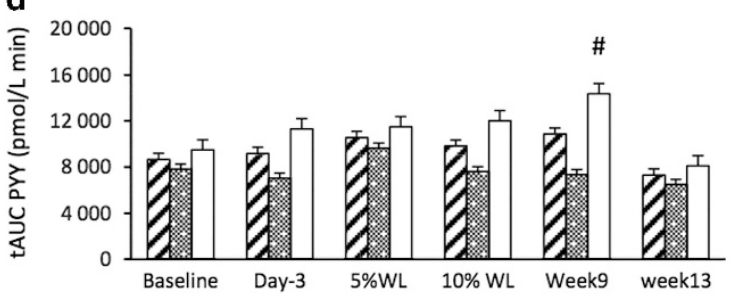

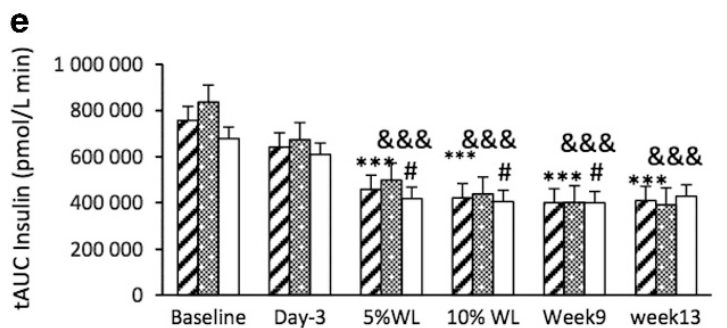

Figure 6. AUC for appetite-related hormones (a: active ghrelin (AG), b: GLP-1, c: CCK, d: PYY and e: insulin) over time in all participants, males and females. Results presented as estimated marginal means \pm s.e.m. Symbols denote significant differences from baseline in all participants: ${ }^{* * *} P<0.001,{ }^{* *} P<0.01$, males: ${ }^{\& \&} P<0.001,{ }^{\&} \& P<0.01$ and ${ }^{\&} P<0.05$ and females: ${ }^{*} P<0.05$. CCK, cholecystokinin; GLP-1, glucagon-like peptide-1; PYY, total peptide YY; tAUC, total area under the curve; WL, weight loss.

appetite were reported, while basal GLP-1 (in males only), basal PYY (in all and males) and CCK AUC (in all) were significantly reduced. Previous studies using ketogenic diets and inducing a similar WL (6-8\%) have systematically shown no change in hunger feelings. ${ }^{18,34-39}$ Even though some of these studies report a significant increase in fullness feelings (both fasting and postprandial), ${ }^{36,38}$ others report no changes in feelings of fullness in the fasting state after WL. ${ }^{34,35,37}$

A study by Adams et al., ${ }^{16}$ where participants with obesity (males and females) underwent 6 weeks of a VLED (7\% WL), reported a reduction in hunger at 90 and $120 \mathrm{~min}$, an increase in fullness at $120 \mathrm{~min}$ postprandial, as well as a decrease in postprandial total GLP-1 (but no changes in fasting). Diepvens et al. ${ }^{39}$, where females with overweight experienced an $11 \% \mathrm{WL}$ with a VLED, reported a significant reduction in basal concentration of AG and no changes in CCK or GLP-1 concentration (either fasting or postprandial). Similar to us, Soenen et al. ${ }^{18}$ reported a significant reduction in basal concentration of PYY after a $6 \% \mathrm{WL}$ (4 weeks VLED).

A recent meta-analysis by Gibson et al. reported that losing weight with a ketogenic diet is associated with a reduction in hunger and increase in fullness feelings. All but one of the studies included in the analyses had average $\beta$-HB plasma concentration around $0.50 \mathrm{mmoll}^{-1.22}$ It is surprising that hunger feelings in fasting in our study were increased on day 3 and $5 \% \mathrm{WL}$, but not at $10 \% \mathrm{WL}$, even though $\beta-\mathrm{HB}$ concentration did not differ from $5 \% \mathrm{WL}$. The reasons for this mismatch between $\beta$-HB concentration and subjective appetite feelings are unknown. However, it can be that participants got used to feeling hungry and that this perception therefore was attenuated overtime. Moreover, a recent review has suggested that other factors such as free fatty acids, reactive oxygen species and microbiota may also play a role. ${ }^{40}$

At week 9, with a $16 \pm 2 \%$ WL and ketosis, no changes in subjective feelings of appetite were seen, with the exception of PFC AUC, which was reduced compared to baseline in all participants and females. Basal active GLP-1 was significantly reduced in males and GLP-1 AUC was increased in females, while CCK AUC was reduced in all participants and males. Only a few studies have looked at the impact of a WL $>10 \%$ under ketosis on appetite. $^{12}$ In the systematic review and meta-analysis from Gibson et $a l^{22}$, a significant increase in fullness, and decrease in hunger feelings were reported while ketotic, with a WL ranging from 5 to $12.5 \mathrm{~kg}$. After 4 weeks of weight stabilisation and without ketosis, the only significant changes observed were increased hunger feelings in fasting (in all participants and females) and increased basal and postprandial concentration of AG.

Sumithran et al. ${ }^{12}$, in a similar WL intervention, reported no changes in subjective feelings of appetite and a significant decrease in basal active GLP-1, but different from our study a significant decrease in basal PYY and CCK, and a significant decrease in postprandial concentration of PYY at week 9 under ketosis. After 2 weeks of weight stabilisation and no ketosis, appetite feelings were increased. Both basal and postprandial concentration of AG were also increased, which is in line with our findings. Opposite to our findings, both basal active GLP-1 and CCK plasma concentration, and postprandial PYY and CCK concentration were reduced. ${ }^{10}$ This discrepancy may be due to differences in the duration of the weight stabilisation period and/ or lack of power. It is possible that more than 2 weeks of weight stabilisation are needed for the concentration of satiety hormones 
to normalise. Another study by Chearskul et al. ${ }^{19}$ with an 8-week VLED (429 kcal per day) in 12 males with obesity who experienced a $15 \% \mathrm{WL}$, did not report any changes in hunger or satiety feelings, or CCK concentration, either fasting or postprandial, immediately after the intervention, while in ketosis. However, 1 week later and without ketosis, a significant reduction in postprandial CCK was described (opposite to our study where no changes were seen). Again, differences in the duration of the stabilisation phase might have impacted on the results. In a recently published study, lepsen et al. ${ }^{41}$ reported a significant increase in fasting and postprandial total ghrelin, and PYY ${ }_{3-36}$ and postprandial concentration of total GLP-1 after a $17 \%$ WL induced with an $810 \mathrm{kcal}$ per day diet over 8 weeks when participants were out of ketosis. Differences in the hormones' fractions measured may account for some of the differences.

The increased hunger feelings and AG plasma concentrations seen after refeeding (week 13) in the present study may have important implications regarding WL outcomes. A recent study has reported that the increase in appetite seen with WL was three times larger than the corresponding reduction in total energy expenditure, highlighting the important role the feedback control of energy intake may have on long-term maintenance of a reduced body weight. ${ }^{33}$

Throughout the study period, a mismatch was apparent between subjective appetite feelings and anticipated relevant appetite-related hormones. Among others, there was an increase in hunger on day $3(2 \pm 1 \% \mathrm{WL})$, despite no changes in appetite hormones except for insulin, and 5\% WL, despite an increase in GLP-1 AUC and a reduction in CCK. Even though this mismatch can derive from lack of power, it is well known that the appetite control system is extremely complex and subjective feelings of appetite are not always correlated with the concentration of appetite-related hormones. ${ }^{42}$ Pre-lunch plasma concentrations of total ghrelin and PYY were also found not to be associated with lunch energy intake in healthy women. ${ }^{43}$ Moreover, a recent review by Holt et al. ${ }^{44}$ concluded that self-reported appetite ratings of appetite cannot reliably predict subsequent energy intake.

As previously described, some sex differences were noted in both subjective feelings of appetite and appetite hormones with progressive WL. The fact that males, as opposed to females, reported no increase in hunger throughout the study (despite increased $A G$ at week $13(16 \pm 2 \% \mathrm{WL})$ ) is surprising. Females were found to have a more sensitive neuronal response to food-related visual cues, which can contribute to the sex differences reported in the present study. Moreover, in our study, females had overall higher fullness AUC, and overall higher basal and AUC for AG, while males had overall higher hunger, desire to eat and PFC AUC. This is in line with previous findings showing that females have a higher satiating response to meals ${ }^{45}$ and lower ratings of hunger and PFC. ${ }^{46}$ It needs to be acknowledged, nevertheless, that with the VLED used in this study, males had a much larger energy deficit per day compared with females, which resulted in a larger overall absolute WL, and this might have contributed to the sex differences reported.

A strength of this study is its design; the fact that multiple measurements were undertaken during progressive $\mathrm{WL}$ under ketosis, and after a period of weight stabilisation and no ketosis. This is important, given that ketosis is thought to modulate appetite. $^{12,22}$ Moreover, subjective and objective aspects of appetite were assessed, both in fasting and after a meal. Compliance with the intervention was monitored throughout and was excellent. The choice of time points is also a strength, given that it allowed to evaluate the impact of minimal, but significant WL (achieved at day 3), 5 and 10\% WL, considered necessary to achieved health benefits, ${ }^{2}$ and large WL (16-17\%) under ketosis vs no ketosis, on appetite outcomes. It is also a strength that we have adjusted for the increased risk of finding statistically significant differences by chance alone (by using Bonferroni adjustment for multiple time comparisons and the Benjamini-Hochberg method for multiple outcome variables). ${ }^{28}$ A limitation of this study is that it may be underpowered to examine sex differences.

This study has important practical implications for patients, clinicians and researchers alike. Opposite to previous reports that the drive to eat is suppressed while under a ketogenic diet, ${ }^{19,22}$ we have shown a transitory increase in hunger from baseline up to 3 weeks on a ketogenic VLED, which then disappear and only come back after refeeding (and no ketosis). This information is of importance because it can influence patients' expectations and adherence to VLEDs.

\section{CONCLUSIONS}

Progressive WL with a ketogenic VLED induces a transient increase in fasting hunger feelings up to $5 \% \mathrm{WL}$ (3 weeks), despite no changes in AG and an increase in active GLP-1 AUC. A WL between 10 and $17 \%$ under ketosis is not associated with increased appetite feelings or AG plasma concentration, despite reduced fasting concentration of total PYY and CCK AUC. Increased hunger and AG plasma concentration return with refeeding (no ketosis) and weight stabilisation. Sex seems to modulate some of the changes in appetite seen with $\mathrm{WL}$, however, larger studies powered to detect sex differences are required to confirm these findings.

\section{CONFLICT OF INTEREST}

The authors declare no conflict of interest.

\section{ACKNOWLEDGEMENTS}

We would like to thank all participants for their time and commitment, Hege Bjøru and Sissel Salater (at the ObeCe, Clinic of Surgery, St. Olav University Hospital) for support with screening and blood collection, Turid Follestad for helping with statistical analysis and Ingrid Hals for support with lab work (both at the Department of Cancer Research and Molecular Medicine, NTNU). The funding for this study is provided by Liaison Committee between the Central Norway Regional Health Authority (RHA) and the Norwegian University of Science and Technology (NTNU). Clinic of Surgery, St. Olav University Hospital, Trondheim, Norway. Allevo, Karo Pharma AS. Sweden, for providing the VLED products (no commercial interest).

\section{REFERENCES}

1 WHO. Obesity and Overweight 2015. Available at http://www.who.int/media centre/factsheets/fs311/en/ (accessed on 15 March 2016).

2 Blackburn G. Effect of degree of weight loss on health benefits. Obes Res 1995; 3 (Suppl 2): 211s-216s.

3 Anderson JW, Konz EC, Frederich RC, Wood CL. Long-term weight-loss maintenance: a meta-analysis of US studies. Am J Clin Nutr 2001; 74: 579-584.

4 Kraschnewski JL, Boan J, Esposito J, Sherwood NE, Lehman EB, Kephart DK et al. Long-term weight loss maintenance in the United States. Int J Obes 2010; 34: 1644-1654.

5 Wing RR, Hill JO. Successful weight loss maintenance. Annu Rev Nutr 2001; 21: 323-341.

6 Rosenbaum M, Leibel RL. Adaptive thermogenesis in humans. Int J Obes 2010; 34 (Suppl 1): S47-S55.

7 Cornier MA. Is your brain to blame for weight regain? Physiol Behav 2011; 104: 608-612.

8 Doucet E, Cameron J. Appetite control after weight loss: what is the role of bloodborne peptides? Appl Physiol Nutr Metab 2007; 32: 523-532.

9 Maclean PS, Bergouignan A, Cornier MA, Jackman MR. Biology's response to dieting: the impetus for weight regain. Am J Physiol Regul Integr Comp Physiol 2011; 301: R581-R600.

10 Leibel RL, Rosenbaum M, Hirsch J. Changes in energy expenditure resulting from altered body weight. N Engl J Med 1995; 332: 621-628.

11 Rosenbaum M, Vandenborne K, Goldsmith R, Simoneau JA, Heymsfield S, Joanisse DR et al. Effects of experimental weight perturbation on skeletal muscle work efficiency in human subjects. Am J Physiol Regul Integr Comp Physiol 2003; 285: R183-R192. 
12 Sumithran P, Prendergast LA, Delbridge E, Purcell K, Shulkes A, Kriketos A et al. Ketosis and appetite-mediating nutrients and hormones after weight loss. Eur $J$ Clin Nutr 2013; 67: 759-764.

13 Sumithran P, Prendergast LA, Delbridge E, Purcell K, Shulkes A, Kriketos A et al. Long-term persistence of hormonal adaptations to weight loss. N Engl J Med 2011; 365: 1597-1604.

14 Fruhbeck G, Rotellar F, Hernandez-Lizoain JL, Gil MJ, Gomez-Ambrosi J, Salvador J et al. Fasting plasma ghrelin concentrations 6 months after gastric bypass are not determined by weight loss or changes in insulinemia. Obes Surg 2004; 14: 1208-1215.

15 Cummings DE, Weigle DS, Frayo RS, Breen PA, Ma MK, Dellinger EP et al. Plasma ghrelin levels after diet-induced weight loss or gastric bypass surgery. $N$ Engl J Med 2002; 346: 1623-1630.

16 Adam TC, Jocken J, Westerterp-Plantenga MS. Decreased glucagon-like peptide 1 release after weight loss in overweight/obese subjects. Obes Res 2005; 13: 710-716.

17 Essah PA, Levy JR, Sistrun SN, Kelly SM, Nestler JE. Effect of weight loss by a lowfat diet and a low-carbohydrate diet on peptide YY levels. Int J Obes 2010; 34: 1239-1242.

18 Soenen S, Hochstenbach-Waelen A, Westerterp-Plantenga MS. Efficacy of alphalactalbumin and milk protein on weight loss and body composition during energy restriction. Obesity (Silver Spring) 2011; 19: 370-379.

19 Chearskul S, Delbridge E, Shulkes A, Proietto J, Kriketos A. Effect of weight loss and ketosis on postprandial cholecystokinin and free fatty acid concentrations. Am J Clin Nutr 2008; 87: 1238-1246.

20 Mars M, de Graaf C, de Groot LC, Kok FJ. Decreases in fasting leptin and insulin concentrations after acute energy restriction and subsequent compensation in food intake. Am J Clin Nutr 2005; 81: 570-577.

21 Pasiakos SM, Caruso CM, Kellogg MD, Kramer FM, Lieberman HR. Appetite and endocrine regulators of energy balance after 2 days of energy restriction: insulin, leptin, ghrelin, and DHEA-S. Obesity (Silver Spring) 2011; 19: 1124-1130.

22 Gibson AA, Seimon RV, Lee CM, Ayre J, Franklin J, Markovic TP et al. Do ketogenic diets really suppress appetite? A systematic review and meta-analysis. Obes Rev 2015; 16: 64-76.

23 Brennan IM, Feltrin KL, Nair NS, Hausken T, Little TJ, Gentilcore D et al. Effects of the phases of the menstrual cycle on gastric emptying, glycemia, plasma GLP-1 and insulin, and energy intake in healthy lean women. Am J Physiol Gastrointest Liver Physiol 2009; 297: G602-G610.

24 Nordic Nutrition Recommendations 2012: norden.org, 2014. Available at: http://www.norden.org/da/tema/tidligere-temaer/tema-2016/nordic-nutritionrecommendation.

25 Scheers T, Philippaerts R, Lefevre J. Patterns of physical activity and sedentary behavior in normal-weight, overweight and obese adults, as measured with a portable armband device and an electronic diary. Clin Nutr 2012; 31: 756-764.

26 Stubbs RJ, Hughes DA, Johnstone AM, Rowley E, Reid C, Elia M et al. The use of visual analogue scales to assess motivation to eat in human subjects: a review of their reliability and validity with an evaluation of new hand-held computerized systems for temporal tracking of appetite ratings. Br J Nutr 2000; 84: 405-415.

27 Rehfeld JF. Accurate measurement of cholecystokinin in plasma. Clin Chem 1998; 44: 991-1001.

28 Benjamini $Y$, Hochberg $Y$. Controlling the false discovery rate: a practical and powerful approach to multiple testing. J R Stat Soc series B 1995; 57: 289-300.

29 Clayton DJ, Creese M, Skidmore N, Stensel DJ, James LJ. No effect of 24 h severe energy restriction on appetite regulation and ad libitum energy intake in overweight and obese males. Int J Obes 2016.

30 Mars M, de Graaf C, de Groot CP, van Rossum CT, Kok FJ. Fasting leptin and appetite responses induced by a 4-day $65 \%$-energy-restricted diet. Int J Obes 2006; 30: 122-128.
31 Doucet E, Pomerleau M, Harper ME. Fasting and postprandial total ghrelin remain unchanged after short-term energy restriction. J Clin Endocrinol Metab 2004; 89: 1727-1732.

32 Cameron JD, Goldfield GS, Riou ME, Finlayson GS, Blundell JE, Doucet E. Energy depletion by diet or aerobic exercise alone: impact of energy deficit modality on appetite parameters. Am J Clin Nutr 2016; 103: 1008-1016.

33 Polidori D, Sanghvi A, Seeley RJ, Hall KD. How strongly does appetite counter weight loss? quantification of the feedback control of human energy intake. Obesity (Silver Spring) 2016; 24: 2289-2295.

34 Hursel R, Westerterp-Plantenga MS. Green tea catechin plus caffeine supplementation to a high-protein diet has no additional effect on body weight maintenance after weight loss. Am J Clin Nutr 2009; 89: 822-830.

35 Kovacs EM, Lejeune MP, Nijs I, Westerterp-Plantenga MS. Effects of green tea on weight maintenance after body-weight loss. Br J Nutr 2004; 91: 431-437.

36 Lejeune MP, Kovacs EM, Westerterp-Plantenga MS. Effect of capsaicin on substrate oxidation and weight maintenance after modest body-weight loss in human subjects. Br J Nutr 2003; 90: 651-659.

37 Lejeune MP, Kovacs EM, Westerterp-Plantenga MS. Additional protein intake limits weight regain after weight loss in humans. $\mathrm{Br} J$ Nutr 2005; 93: 281-289.

38 Westerterp-Plantenga MS, Lejeune MP, Kovacs EM. Body weight loss and weight maintenance in relation to habitual caffeine intake and green tea supplementation. Obes Res 2005; 13: 1195-1204.

39 Diepvens K, Soenen S, Steijns J, Arnold M, Westerterp-Plantenga M. Long-term effects of consumption of a novel fat emulsion in relation to body-weight management. Int J Obes 2007; 31: 942-949.

40 Paoli A, Bosco G, Camporesi EM, Mangar D. Ketosis, ketogenic diet and food intake control: a complex relationship. Front Psychol 2015; 6: 27.

41 lepsen EW, Lundgren J, Holst JJ, Madsbad S, Torekov SS. Successful weight loss maintenance includes long-term increased meal responses of GLP-1 and PYY3-36. Eur J Endocrinol 2016; 174: 775-784.

42 Burton-Freeman B, Davis PA, Schneeman BO. Plasma cholecystokinin is associated with subjective measures of satiety in women. Am J Clin Nutr 2002; 76: 659-667.

43 Doucet E, Laviolette M, Imbeault P, Strychar I, Rabasa-Lhoret R, Prud'homme D. Total peptide $Y Y$ is a correlate of postprandial energy expenditure but not of appetite or energy intake in healthy women. Metabolism 2008; 57: 1458-1464.

44 Holt GM, Owen LJ, Till S, Cheng Y, Grant VA, Harden CJ et al. Systematic literature review shows that appetite rating does not predict energy intake. Crit Rev Food Sci Nutr 2016. Available at: http://www.tandfonline.com/doi/full/10.1080/10408398. 2016.1246414.

45 Cornier MA, Salzberg AK, Endly DC, Bessesen DH, Tregellas JR. Sex-based differences in the behavioral and neuronal responses to food. Physiol Behav 2010; 99: 538-543.

46 Gregersen NT, Moller BK, Raben A, Kristensen ST, Holm L, Flint A et al. Determinants of appetite ratings: the role of age, gender, BMI, physical activity, smoking habits, and diet/weight concern. . Food Nutr Res 2011; 55: 1-10.

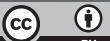

This work is licensed under a Creative Commons Attribution 4.0 International License. The images or other third party material in this article are included in the article's Creative Commons license, unless indicated otherwise in the credit line; if the material is not included under the Creative Commons license, users will need to obtain permission from the license holder to reproduce the material. To view a copy of this license, visit http://creativecommons.org/licenses/ by/4.0/

(c) The Author(s) 2017

Supplementary Information accompanies this paper on International Journal of Obesity website (http://www.nature.com/ijo) 